\title{
User Perception on Electronic Medical Records Support for Treatment in Mama Lucy and Mbagathi Hospital
}

\begin{abstract}
Millicent A. Awuor* and Peter Wamae
Kenyatta University

Email:*milliesimiyu@gmail.com

Abstract

Electronic health records offer a valuable resource to improve health surveillance an evaluation as well as informing clinical decision making. This has been introduced in many different settings including low and middle income countries. The focus on healthcare as one of Kenya's big four agenda will greatly be achieve in an EMR environment. The objective of this study was to establish users ' perception on EMR support for treatment in Mama Lucy and Mbagathi hospital. The study employed technology acceptance model and was guided by descriptive research design. A sample size of 238 out of a population of 630 employees working at Mama Lucy Kibaki hospital and Mbagathi hospital was used. Primary data was collected using questionnaires. Additional data was collected from secondary sources using documentary analysis. Analysis was done by SPSS Version 23.0, and presented in form of tables and charts. The findings confirmed that Mama Lucy and Mbagathi hospital service providers perceived that an EMR system is the best and easy use during service delivery compare to use paper. They also believe that there is improvement in the quality of care and services for the patients; use of EMRs speeds up registration of patient information; and it reduces medication and prescription errors in the hospitals. This study recommends that; the two facilities should make sure that there is adoption of a fully electronic medical records system in so as to improve the quality of delivery of services to the patients to receive better perception. Both Mama Lucy and Mbagathi hospitals should train the service providers and emphasize on the benefits of EMR so as to improve perceptions of EMR of the users as they interact with the system.
\end{abstract}

Keywords: User Perception, Electronic Medical Records, Support for Treatment, Mama Lucy Hospital, Mbagathi Hospital

DOI: $10.7176 / \mathrm{IKM} / 10-7-08$

Publication date: December $31^{\text {st }} 2020$

\subsection{Introduction}

Medical record, a documentation of care given to the patient whether in paper or electronic form is supposed to support treatment and follow up, clinical research, planning and policy formulation. Just like any other authentic record, there are used for providing evidence on treatment and other medical legal issues. At the minimum, a typical medical record whether electronic or print carries medical history, diagnoses, medications, treatment plans, immunization dates, allergies, radiology images, and laboratory and test results. According to Casey, Schwartz, Stewart, \& Adler (2016) the primary function of electronic medical records is treatment.

Electronic medical records system (EMRS) is real-time computer based systems for documenting clinical details and other auxiliary support. Such system makes information available instantly and securely to authorized users. An EMR system is built to go beyond standard clinical data collected in a provider's office and can be inclusive of a broader view of a patient's care. Through EMR, researchers have been able to conduct epidemiologic investigations, ranging from cross-sectional studies within a given hospital to longitudinal studies on geographically distributed patients. It empowers both care givers and patients to make more informed health decisions, on clinical and research related issues. (Centres for Medicare \& Medicaid Services, 2015).

It has been reported that EMR enhances viewing of medical history in users preferred order and hence shortening the time required for clinical reference (Ben-Assuli, Shabtai, Leshno \& Hill, 2013). According to Wamae (2015) EMRS has the potential of the following functionalities: EMR Potential in Care Structuring and Follow-up. In his findings he states that electronic medical records have proven to be very successful in providing a structure that helps doctors record their notes about patients, and view those notes subsequently in a manner that quickly gives them a good understanding of that patient history. Evidence also indicate that medical record can explicitly be organized around the problem list, indicating which problems the note addresses, and summarizing of the medical plan in regards to the others. Problem list enables clinicians to deal with the itemized patients problem 
list and remove the problems from the list as they are resolved; EMR Potential in Clinical Decision Support. The EMR strength in this area is seen in its potential to support decision making by providing information specific to decision steps outlined in clinical guidelines. When a medical record is organized in a standard way, the computer can begin to help in a limited way with the medical decision making process itself.

Another reported strength of EMR is the ability to catch and flag human errors. Considering the large number of medications in common usage and the fact that most patients take several drugs simultaneously, physician are faced with challenges of keeping track of all the drug interactions; EMR Potential in Clinical Quality Assurance and Monitoring. The potential of EMR in quality assurance has been noted in its ability to analyse data and provide indicators which can be used for evaluating quality of care improve coordination by making information available at the point of care, especially if implemented well in a health facility; and lastly he stated that EMR Potential for Online Health Care.

Evidence based research has shown that the main advantages of EMRS include; expanded use and share of medical information, costs, linkage to vital or other records, and accessibility. It has also been projected that EMR opportunities will increase as new technologies allow patient data capture without input from medical professionals. For example, patients can self-report data on a patient portal that links to their EMRS. A future with web based systems is anticipated to enable better care adherence, improved patient-provider relationships, and improved patient autonomy and selfefficacy (Otte-Trojel, de Bont, Rundall, \& van de Klundert, 2014).

In most countries, EMR implementation has faced numerous challenges such as adherence to government guidelines and policy. Since 1994, Kenya has made several initiatives in the integration of ICT in health. such as the development of Standards and guidelines for electronic medical systems in Kenya. The use EMR systems in was introduced in Kenya's Hospitals in 2005. However, though the adoption of electronic health records use has increased with the years, the patterns are still inconsistent and the adoption rate has been slow in comparison to what the ministry of health anticipated despite the highlighting of benefits and only about $7 \%$ of health care practitioners use them. Reporting from NGO's and small private health facilities is far lower than their share of health service (WHO 2011). The biggest question in the health care sector should be, how is data collected from these clinics and how is it integrated into the national health care system for proper planning. With reference to the advantages given for having a digitized health system, the large private and some government hospitals have integrated the EMR systems into their work schedule but the big gap still lies in the trend of adoption of these systems by the public health facilities and what challenges could they be facing in this adoption process (WHO, 2011).

\subsection{Research Methods}

Descriptive design was deemed necessary for this study, because it aims at describing the current

EMR situations for the two hospitals. The study was carried out in Nairobi County, Kenya at Mama Lucy Kibaki Hospital and Mbagathi Hospital in Nairobi County, Kenya. These hospitals were selected because of their similarity in operations and size and the fact that there are the government and expected to adhere to government standards policies and procedures. A sample size of 238 out of a population of 630 employees working at Mama Lucy Kibaki hospital and Mbagathi hospital was used. The researcher preceded the actual data collection with a pilot study. This enabled the researcher to validate the instruments to achieve better data and at the same time get to know if the chosen sample was viable. The pilot institutions were Kenyatta National hospital. The researcher administered questionnaires and assess if each question gives an adequate range of responses. Data was collected using questionnaires. The quantitative data was collected using structured questionnaires. The questionnaires were administered to the respondents. Analysis was done by SPSS Version 23.0, and presented in form of tables and charts.

\subsection{Results}

\subsection{Response Rate}

Out of 238 respondents, 230 questionnaires were returned back representing 96.6\% Mulusa (1990) explains that $50 \%$ return rate is adequate, $60 \%$ good and above $70 \%$ is very good. The high response rate may be attributed to the fact that the study was touching on very important aspects that contributed to hospital service delivery 


\subsection{Distribution of Respondents by Gender}

The study gathered data on respondents' gender which is summarized in figure 1.

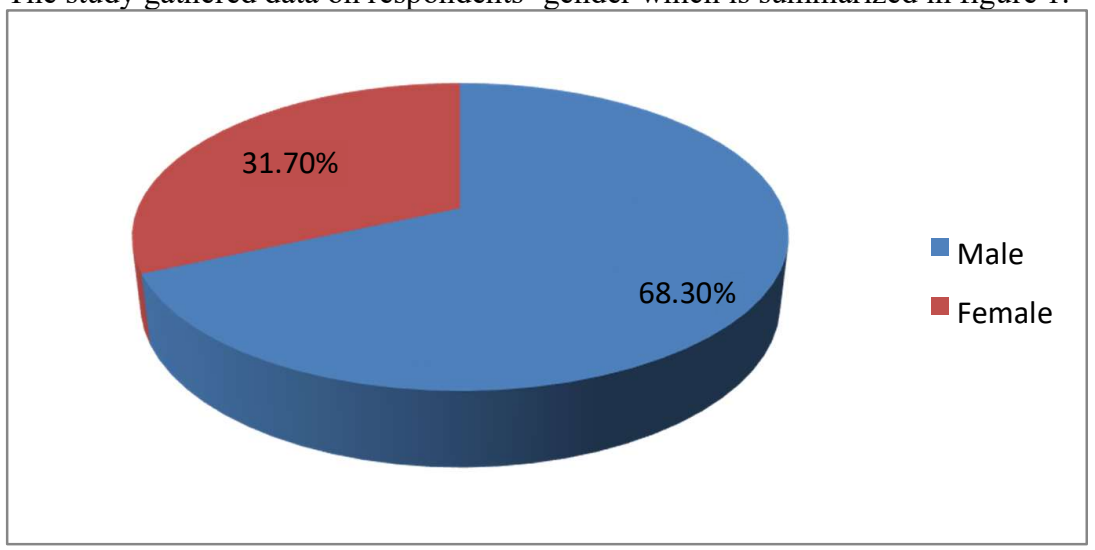

Figure 1: Gender of Respondents

From the data presented in figure 1, it clearly indicates that $68.30 \%$ were males while $31.7 \%$ were females. The results imply that most of the study respondents were males.

\subsection{Distribution of Respondents by Position}

Figure 2 above shows results on the position held in the health facility by respondents.

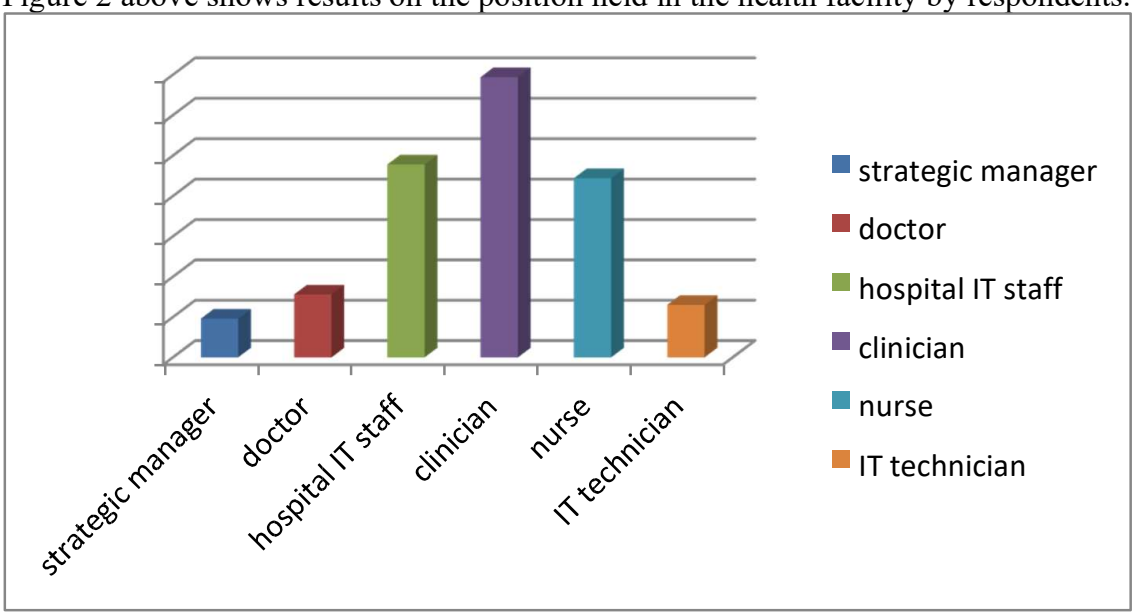

Figure 2: Position in the Facility, $(n=230)$

The majority of the respondents in the study were clinicians $34.7 \%$, Hospital staff $23.9 \%$, nurses

$22.2 \%$, Doctors $7.8 \%$, It Technician $6.5 \%$ while $4.8 \%$ were strategic officers.

\subsection{Academic Qualifications of Respondents $(n=230)$}

The study also gathered data on respondent's academic qualifications which is presented in figure 3. 


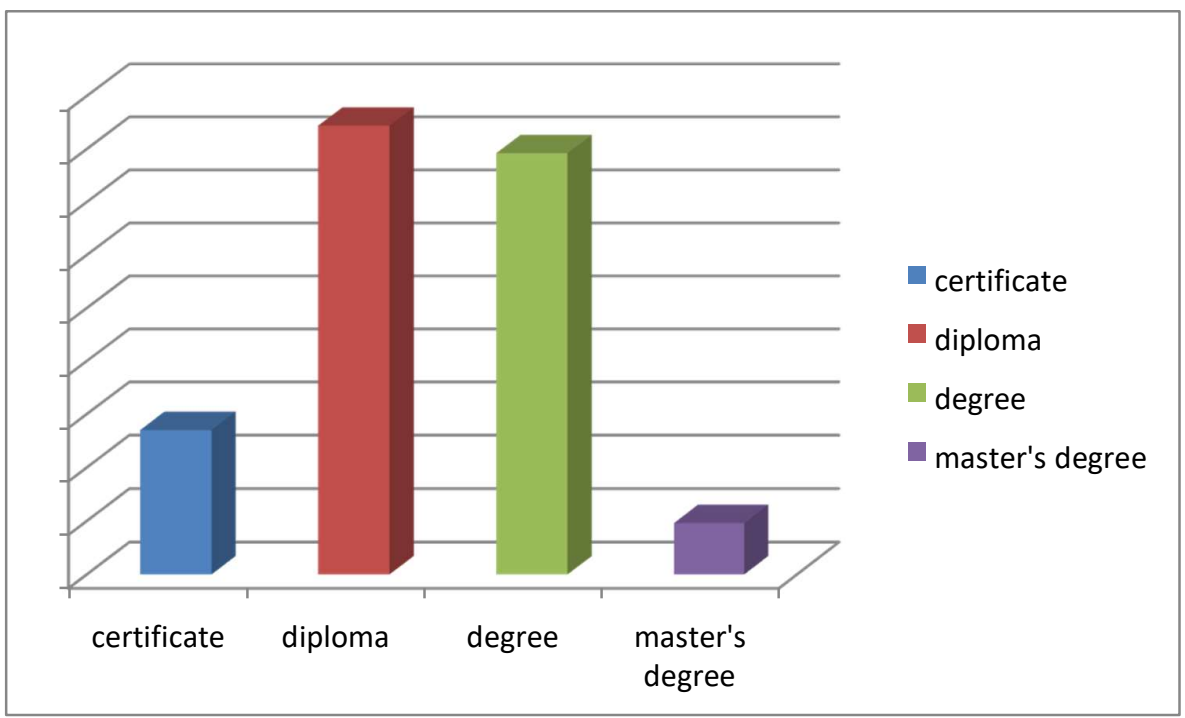

Figure 3: Academic Qualifications of Respondents $(\mathbf{n}=\mathbf{2 3 0})$

From figure 3, most of the respondents were diploma holders (42.2\%), 39.6\% were degree holders,

$13.5 \%$ certificate holders while only $4.8 \%$ were master's degree holders.

\subsection{Age of Respondents}

Figure 4 shows age ranges of the study respondents.

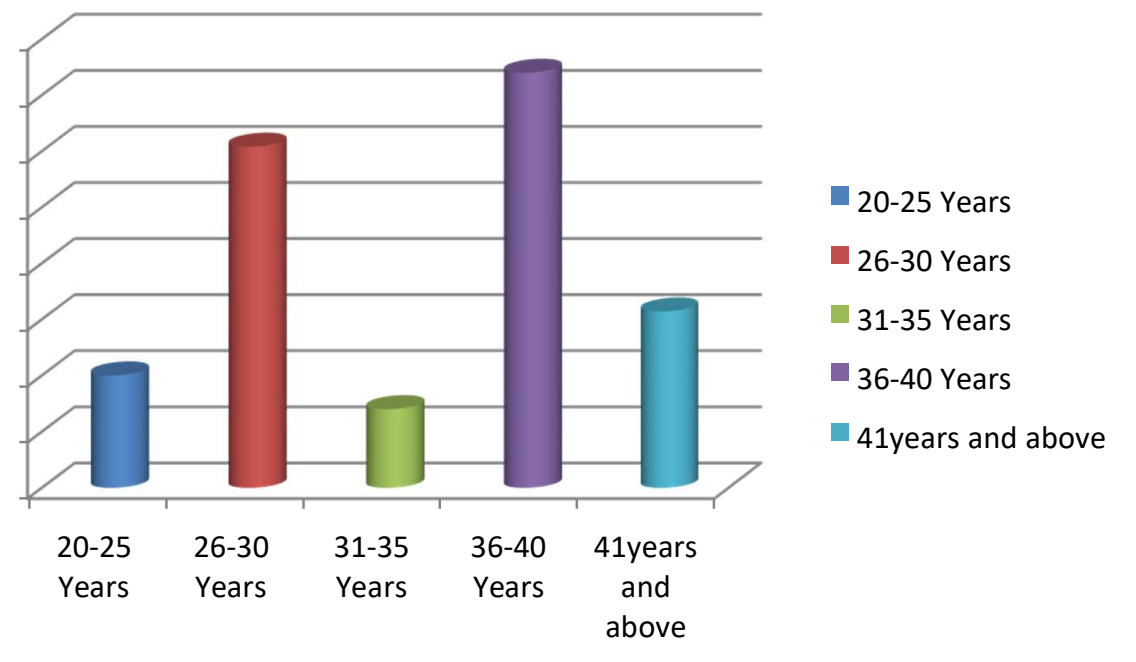

Figure 4: Age of Respondents

From the findings presented in figure 4, majority of the respondents $37.0 \%$ were within the age bracket of $36-40$ years, $30.4 \%$ between $26-30$ years, and $15.7 \% 41$ years and above, $10 \%$ between 20-25 years while only $7.0 \%$ were within $31-35$ years.

\subsection{Staff Competence and Training}

The study sought to find out from the respondents on the extent on which adoption of EMR affects service delivery. Results are discussed in table 1 
Table 1: Staff Competence and Training

\begin{tabular}{|c|c|c|c|c|c|c|c|c|c|c|}
\hline \multirow[b]{2}{*}{ Factor } & \multicolumn{2}{|l|}{ SA } & \multicolumn{2}{|l|}{$\mathbf{A}$} & \multicolumn{2}{|l|}{$\mathbf{U}$} & \multicolumn{2}{|l|}{ D } & \multicolumn{2}{|l|}{ SD } \\
\hline & Fre & $\%$ & Fre & $\%$ & Fre & $\%$ & Fre & $\%$ & Fre & $\%$ \\
\hline $\begin{array}{l}\text { General computer competence affect } \\
\text { our utilisation of EMR in our hospital }\end{array}$ & 92 & 40.0 & 73 & 31.7 & 51 & 22.2 & 14 & 6.1 & 0 & 0 \\
\hline $\begin{array}{l}\text { Lack of knowledge about EMR } \\
\text { influence its adoption } \\
\text { and utilisation }\end{array}$ & 60 & 26.1 & 89 & 38.7 & 43 & 18.7 & 38 & 16.5 & 0 & 0 \\
\hline $\begin{array}{l}\text { Lack of use of EMR technology } \\
\text { hinders its usage and adoption }\end{array}$ & 49 & 21.3 & 69 & 30.0 & 88 & 38.3 & 24 & 10.4 & 0 & 0 \\
\hline $\begin{array}{l}\text { Health professionals would prefer not } \\
\text { to use computers directly but would } \\
\text { rather someone else do the computer- } \\
\text { related work for them }\end{array}$ & 51 & 22.2 & 79 & 34.3 & 29 & 12.6 & 51 & 22.2 & 20 & 8.7 \\
\hline $\begin{array}{l}\text { The fear of using technology is a } \\
\text { barrier to the adoption of EMR } \\
\text { systems by health care professionals. }\end{array}$ & 73 & 31.7 & 105 & 45.7 & 28 & 12.2 & 24 & 10.4 & 0 & 0 \\
\hline
\end{tabular}

It is evident from table 1 general computer competence affect our utilisation of EMR in our hospital with 92(40.0\%) strongly agreed, 73(31.7\%) agreed, 51(22.2\%) were uncertain while 14(6.1\%) disagreed. Distribution of respondents in regard to lack of knowledge about EMR influencing its adoption and utilisation in Mbangathi and Mama Lucy hospital is also shown in table 4.1. it is evident that most of the respondents $89(38.7 \%)$ agreed that lack of knowledge about EMR influences its adoption and utilisation in Mbangathi and Mama Lucy hospital, $60(26.1 \%)$ strongly agreed, $43(18.7 \% 0$ were uncertain while $38(16.5 \% 0$ disagreed. The study also sought to find out from the respondents if lack of use of EMR technology hinders its usage and adoption in the hospitals, it is indicated that $88(38.3 \%)$ of the respondents were uncertain, $69(30.0 \%)$ agreed, $49(21.3 \%)$ strongly agreed while $24(10.4 \%)$ disagreed, showing that the respondents are aware that lack of use of EMR technology hinders its usage and adoption in the hospitals.

On finding out from the respondents if health professionals would prefer not to use computers directly but would rather someone else do the computer-related work for them, it is evident from table 1 that $79(34.3 \%)$ of the respondents agreed to it, $51(22.2 \%)$ strongly agreed that in their hospital professionals prefer not to use computers directly but someone else do the computerrelated work for them, 51(22.2\%) disagreed while 20(8.7\%) strongly disagreed.

The results from the respondents also shows that majority of the respondents $105(45.7 \%)$ agreed that the fear of using technology is a barrier to the adoption of EMR systems by health care professionals, 73(31.7\%) strongly agreed, 28.4\% were uncertain while 24(10.4\%) disagreed.

\subsection{User Perception on Adaptation and use of EMR}

The study analysed different variables to determine whether EMR had positive effects on service delivery, their perceptions on EMR and how they viewed EMR in their day to day duties in health sector. The results are indicated in 4 table 5 and 6.

\subsection{User Perceived Effect of EMR on Service Delivery}

The study results indicated that $100 \%$ ( 230) of the respondents were of the idea that EMR had a positive effect on the delivery of services in the hospitals. 
Table 4: Ranking of the Perceptions of Respondents Statement

\begin{tabular}{|c|c|c|c|c|c|c|c|c|c|c|}
\hline & \multicolumn{2}{|c|}{ Strongly agree } & \multicolumn{2}{|c|}{ Agree } & \multicolumn{2}{|c|}{ undecided } & \multicolumn{2}{|c|}{ disagree } & \multicolumn{2}{|c|}{$\begin{array}{l}\text { Strongly } \\
\text { disagree }\end{array}$} \\
\hline & Fre & $\%$ & Fre & $\%$ & Fre & $\%$ & Fre & $\%$ & Fre & $\%$ \\
\hline $\begin{array}{l}\text { Use EMRs improve the quality of care } \\
\text { and services to the in the hospital }\end{array}$ & 115 & $50 \%$ & 58 & 25.2 & 0 & 0 & 57 & 24.8 & 0 & 0 \\
\hline $\begin{array}{l}\text { Having an EMR speeds up } \\
\text { registration of general information of } \\
\text { the patient. }\end{array}$ & 100 & 43.5 & 73 & 31.7 & 0 & 0 & 0 & 0 & 57 & 24.8 \\
\hline $\begin{array}{l}\text { Use of EMR system helps reduce } \\
\text { errors in medication and prescription }\end{array}$ & 90 & 39.1 & 70 & 30.4 & 50 & 21.7 & 40 & 17.4 & 0 & 0 \\
\hline $\begin{array}{l}\text { With an EMR system, the quality of } \\
\text { data entered is high. }\end{array}$ & 130 & 56.5 & 45 & 19.5 & 0 & 0 & 55 & 23.9 & 0 & 0 \\
\hline
\end{tabular}

From table 4 the results indicate that 115(50\%) strongly agreed that use EMRs in hospitals improves the quality of care and services delivered to the patient, 58(25.2\%) agreed while 57(24.8\%) of the respondents disagreed.

Looking at another item on "Having an EMR speeds up registration of general information of the patient" $100(43.5 \%)$ of the respondents strongly agreed that by use of EMR registration of general information of the patient is done faster, $73(31.7 \%)$ agreed while $57(24.8 \%)$ of the respondents strongly disagreed.

Further the study sought to find out from the respondents if EMR system can help reduce errors in medication and prescription, $90(39.1 \%)$ of the respondents strongly agreed that helps to reduce errors, $70(30.4 \%)$ agreed, $50(21.7 \%)$ were undecided while 40(17.4\%) disagreed.

Also from table 4 respondents strongly agreed 130(56.5\%) that with EMR systems, there is improved of quality of data entered making it high. 45(19.5\%) agreed while 55(23.9\%) disagreed

Table 5: Impaction of EMR

\begin{tabular}{|c|c|c|c|c|c|c|c|c|}
\hline & GI & & Improve & & slightly & & Not im & roved \\
\hline & Fre & $\%$ & Fre & $\%$ & Fre & $\%$ & Fre & $\%$ \\
\hline Patient turn- around time & 0 & 0 & 20 & 8.7 & 62 & 27.0 & 148 & 64.3 \\
\hline Increase in doctor patient time & 0 & 0 & 12 & 5.2 & 57 & 24.8 & 161 & 70.0 \\
\hline Quality of documentation & 0 & 0 & 30 & 13.0 & 101 & 43.9 & 99 & 43.0 \\
\hline Information sharing & 0 & 0 & 77 & 33.5 & 45 & 19.6 & 108 & 47.0 \\
\hline Availability of information & 0 & 0 & 101 & 43.9 & 92 & 40.0 & 37 & 16.1 \\
\hline $\begin{array}{l}\text { Availability of information for structured } \\
\text { clinical decision }\end{array}$ & 0 & 0 & 25 & 10.9 & 131 & 57.0 & 74 & 32.2 \\
\hline
\end{tabular}

Results in table 5, 148(64.3\%) of the respondents said that patient turnaround time in the hospitals had not improved due to introduction of EMR, 62(27.0\%) noted that patient turnaround time slightly improved, while only $20(8.7 \%)$ said that patient time had improved. Results imply that patient turnaround time hadn't improved despite the introduction of EMR. 
On finding out if the implementation of EMR in the two hospitals had led to improvement in increase in patient doctor time, majority of the respondents $161(70.0 \%)$ said that it hasn't improved, $57(24.8 \%)$ slightly improved while only $12(5.2 \%)$ said that the patient doctor time improved. Looking at the findings it is seen that still with the introduction of EMR in the health sector there is little improvement in patient doctor time during hospital visitation.

Quality of documentation supported by EMR in the two hospitals was also looked at, from the results 99(43.0\%) of the respondents said that quality of documentation has not improved, 101(43.9\%) slightly improved while $30(13.0 \%)$ improved showing that with the use of EMR in the health sector there is a slight improvement in the quality of documentation. Information sharing had not improved with 108(47.0\%), 77(33.5\%) said that there was improvement in information sharing while 45(19.6\%) said that it had slightly improved. Averagely there is improvement in information sharing in hospitals with use of EMR.

Availability of information for structured clinical decision was also looked at; from table 4, 131(57.0\%) of the respondents said that information for structured clinical decision had slightly improved after implementation of EMR in the hospitals, 74(32.2\%) said it had not improved while 25(10.9\%) had improved. It is implied that EMR has slightly impacted slightly on availability of information for structured clinical decision making.

\subsection{Provision of EMR Support}

Table 6 shows results on provision of EMR support in Mama Lucy and Mbangathi hospital

Table 6: Provision of EMR Support

\begin{tabular}{|c|c|c|c|c|c|c|c|c|c|c|}
\hline \multirow[b]{3}{*}{ EMR modifications } & \multicolumn{4}{|c|}{ Strongly agree Agree } & \multicolumn{2}{|c|}{ undecided } & \multicolumn{2}{|c|}{ disagree } & \multicolumn{2}{|c|}{$\begin{array}{l}\text { Strongly } \\
\text { disagree }\end{array}$} \\
\hline & Fre & $\%$ & Fre & $\%$ & Fre & $\%$ & Fre & $\%$ & Fre & $\%$ \\
\hline & 40 & 17.4 & 0 & 0 & 0 & 0 & 85 & 37.0 & 105 & 45.7 \\
\hline When system is down & 73 & 31.7 & 105 & 45.7 & 28 & 12.2 & 24 & 10.4 & 0 & 0 \\
\hline Continuity training & 25 & 10.9 & 131 & 57.0 & 0 & 0 & 0 & 0 & 74 & 32.2 \\
\hline
\end{tabular}

Analysis of data collected on item, "EMR modifications" shows that $105(45.7 \%)$ strongly disagreed that that EMR support is provided during EMR modification, 85(37.0\%) disagreed while only 40(17.4\%) agreed that they gave support. From the results it is indicated that there is few support provided by EMR in the hospitals.

\subsection{Discussion}

The respondents at the two facilities perceived that an EMR system was easy to use when dealing with service delivery as compared to paperwork, improve the quality of care and services, speeds up registration of general information, reduce medication and prescription errors, the quality of data entered is high, improves the quality of treatment provided, shortens patient waiting time, allowed for transparency and accountability of how patients' funds were used through receipts and invoices. This agrees with the study of Shachak and Reis (2009) that posited that many clinicians and policy-makers believe that the quality of medical care will increase through the use of EMR, through reductions in medical errors, increased availability of real-time information and decision support. The finding further revealed that the respondent perceived the system to be environmental friendly, reliable, the cost of EMR implementation and maintenance is not higher than the benefits achieved after use and patient interaction with healthcare practitioners was not interrupted by EMR systems.

These findings concur with Obwoge, and Kahoro (2019) EMRS sytem have greater benefit interms of cost of implementation and maintenance. The study also revealed that respondents agreed that use EMRs in hospitals improves the quality of care and services delivered to the patient. Having an EMR speed up registration of general information of the patient at the hospitals, reduction in errors in medication and prescript was also observed by use EMR system. There is also improved of quality of data entered in the systems with EMRs. Similar views are shared by Ajami and Bagheri- 
Tadi, (2013) who posits that Using of EMRS is a quality improvement program in the medical science field as it seeks to replace the traditional paper-based technique The respondents perceived increase in the productivity of the providers and the hospital, from the results there is a decrease in the turnaround time of patients. This is because of the use of EMR which has led to improved access to new, stored, and archived information and reduced movement time among patients. Respondents stated that there was an increase in use of computers to input patient data as compared to the use of paper, they also agree that generally there was less time spent in the management of patients. This buttress a study Evans, (2016) on Electronic health records: then, now, and in the future. Which stated that electronic records save time and has greater output.

There was also general perception of improvement in information sharing in hospitals with use of EMR. Availability of information for structured clinical decision had improved after implementation of EMR in the hospitals. Scott, Pillans, Barras, and Morris, (2018) use of EMR system can lead to improved clinical decision support by a factor of $24 \%$ which leads to influencing prescribing behavior and cost savings to hospitals by recommending to clinicians' alternative treatment methods that can be as effective and cheaper. This ensures that costly treatment measures are only utilized in cases in which they offer better outcomes than the cheaper methods.

\subsection{Conclusion}

In conclusion from the summary of findings the service providers at the two hospitals perceived that an EMR system is the best and easy use during service delivery compare to use paper, they also believe that there is improvement in the quality of care and services for the patients, use of EMRs speeds up registration of patient information, it reduces medication and prescription errors in the hospitals. The EMR systems has made patient providers work easier. they can easily access patient information, leading to good productivity. There was perception of increase in the productivity of the providers and the hospital, decrease in the turnaround time of patients. This is because of the use of EMR which has led to improved access to new, stored, and archived information and reduced movement time among patients.

\subsection{Recommendations}

This study recommends that; Both Mama Lucy and Mbagathi hospitals should train the service providers and emphasize on the benefits of EMR so as to improve perceptions of EMR of the users as they interact with the system; The administrations of the two hospitals should make sure they work towards coming up with the capacity of the hospitals so as to improve on the use of technology EMRs; and The hospitals administration, doctors and management should enhance and lead in the use the EMRs making sure the health providers are supported, trained on EMRS, have EMRS leaders at hospitals to reinforce EMRS training and communicate on EMRs goals by campaigning against a paper-less office and letting them know its benefits to have better perception of the system.

\section{REFERENCES}

Ajami, S., \& Bagheri-Tadi, T. (2013). Barriers for adopting electronic health records (EHRs) by physicians. Acta Informatica Medica, 21(2), 129.

Ben-Assuli, O., Shabtai, I., Leshno, M., \& Hill, S. (2013). Improving Medical Decision-Making Using Electronic Health Record Systems.

Casey, J. A., Schwartz, B. S., Stewart, W. F., \& Adler, N. E. (2016). Using electronic health records for population health research: a review of methods and applications. Annual review of public health, 37, 61-81

Centers for Medicare \& Medicaid Services (CMS), HHS. (2015). Medicare and Medicaid Programs; Electronic Health Record Incentive Program--Stage 3 and Modifications to Meaningful Use in 2015 through 2017. Final rules with comment period. Federal register, 80(200), 62761.

Evans, R. S. (2016). Electronic health records: then, now, and in the future. Yearbook of medical informatics, (Suppl 1), S48. 
Obwoge, R. O., \& Kahoro, E. W. Effects of Electronic Medical Records in Service Delivery at Kijabe Mission Hospital, Kiambu County, Kenya.

Otte-Trojel, T., de Bont, A., Rundall, T. G., \& van de Klundert, J. (2014). How outcomes are achieved through patient portals: a realist review. Journal of the American Medical Informatics Association, 21(4), 751-757.

Scott, I. A., Pillans, P. I., Barras, M., \& Morris, C. (2018). Using EMR-enabled computerized decision support systems to reduce prescribing of potentially inappropriate medications: a narrative review. Therapeutic advances in drug safety, 9(9), 559-573.

Shachak, A., \& Reis, S. (2009). The impact of electronic medical records on patient-doctor communication during consultation: a narrative literature review. Journal of evaluation in clinical practice, 15(4), 641-649.

Wamae, P. (2015). Implementation of Electronic Medical Records in Kenyan Public Hospitals: Challenges and Opportunities (Doctoral dissertation, Kenyatta University). 